\title{
Design optimization of the plough working surface by computerized mathematical model
}

\author{
Andrea Formato ${ }^{1 *}$, Domenico lanniello', Francesco Villecco², Tony Luigi Leopoldo Lenza², \\ Domenico Guida ${ }^{2}$
}

${ }^{1}$ Department of Agricultural Science, University of Naples "Federico II", Italy, Via Università 100, 80055, Portici (Napoli), Italym, 'Department of Industrial Engineering, University of Salerno, Italy, Via Giovanni Paolo II, 13284084 Fisciano (SA) Italy

\section{A B S T R A C T}

\begin{abstract}
In this paper, a procedure for the optimization of the working surface of a plough for a soil type considered and to analyze the efficiency, is performed. It fits in the set of numerical - experimental techniques used for the improvement of the energy performance related to ploughing of agricultural soil. In the first part of this paper, it describes how to generate a family of working surfaces for assigned geometrical and process parameters; latter, by mean the use of a physical-mathematical model which describes the soil - plough interaction, it is examined the draught resistance changing in function of the geometric and process parameters for a soil considered, aimed to optimize the shape. A commercially available plough, subsequently, was examined and, applying such methods, its parametric representation and the optimized surface were obtained for the examined soil.
\end{abstract}

Keywords: Design optimization; Plough working surface; Soil-tool interaction; Soil mechanics

\section{INTRODUCTION}

Tillage has many unknowns due to the variability of the characteristic physical parameters of the soil in which the tool interacts. (Formato et al., 2004; Gill and Vanden Berg, 1968; Jayasuriya and Salokhe 2001; Jeshvaghani et al., 2013).The evidence of what is said is shown both in the different shapes used for the surface of plough, and in the difficulties of manufacturers to meet the needs of various users operating with different types of agricultural soils. Furthermore, the use of large amounts of energy, used for this type of soil working, is a further important reason to optimize the geometry of these surfaces in order to reduce the powers required and energy cost. (Formato, 2005; Formato et al., 2013; Mouazen and Ramon 2008; Jia, 2004; Ren et al., 2001; Soni and Salokhe; 2006a; Soni and Salokhe; 2006b; Soni et al, 2007; Vilde, 2004; Vilde and Tanas, 2005). Therefore, given the importance of this type of tool, which, with its overturning action, replaces the use of herbicides for weed, a theoretical and numerical-experimental research was performed to determine the design parameters of the working surfaces in relation to the characteristics of the soil considered.
This should reduce the use of empirical component, currently present in the design and construction of these tools, and to indicate new geometry forms suitable to different working conditions. Therefore in this report the possibility of providing a forecast-analytical support to the study of soil-plough interaction is shown. The final goal of the research is summarized in the concrete possibility of identifying effective numerical models with which to perform the design of the plow working surfaces, in reference to a cycle of shape optimization, with a fixed function of the minimum of draught force, a work quality satisfactorily for agronomic use and assigned operating conditions. The above said is united with a process which allows to obtain the dimensioned construction drawings, in order to realize the full cycle of automation of the industrial design. (Formato et al. 2004b; Formato et al., 2005; Formato and Carillo, 2008a; Formato and Carillo, 2008b; Godwin et al., 2007). From an agronomic point of view, the working of agricultural soil is one of the most important phases of the agricultural process, and it is the most energy consuming. It changes the structure of the soil by mechanical actions such as cutting, pressing, grinding, and overturning. The geometry

\footnotetext{
${ }^{*}$ Corresponding author:

Andrea Formato, Department of Agricultural Science, University of Naples “Federico II”, Italy, Via Università 100, 80055, Portici (Napoli), Italy. E-mail: formato@unina.it 
of the plough working surface is generally composed, by a proper tool, the ploughshare, to which is entrusted with the task of cutting the soil slice during its going forward, and the moldboard, to which is entrusted with the task of crush, move sideways and overturn the slice thus generated. This working surface is complex and the work quality and the energy requirements of processing depends on it. Among the design approaches, which over time have been developed, of great interest is the one under which the moldboard and the ploughshare are "designed" simultaneously. This approach is inspired by the fundamental theoretical considerations of Goryachkin, 1968; according to which the study of the geometry of any tool for soil working can be reduced to tetrahedral schema. The working angles of nominal geometry must combine the efficacy and efficiency required to allocated function. On the measure of the efficiency, it will be discussed in the second part of this work, while the efficacy can only be assessed ex post, through targeted field-testing.

\section{MATERIALS AND METHODS}

\section{Geometric description of the plough working surface} It is assumed that the working surface belongs to the family of ruled surfaces, represented by the general parametric vector equation:

$$
S(u, v)=Q(u)+v \underline{r}(u)
$$

according to which the generic point, $S(u, v)$, of the surface is obtained by translating by a quantity $v$ each point of the generic parametric curve $Q=Q(u)$ - directrix equation - along a direction $\underline{r}=\underline{r}(u)$ - generatrix vector equation (Fig. 1). For each set value $u=u_{0}$, $S\left(u_{0}, v\right)=Q\left(u_{0}\right)+v \underline{r}\left(u_{0}\right)$ is a straight line passing through the point $Q\left(u_{0}\right)$ with direction $\underline{r}\left(u_{0}\right)$. The corresponding

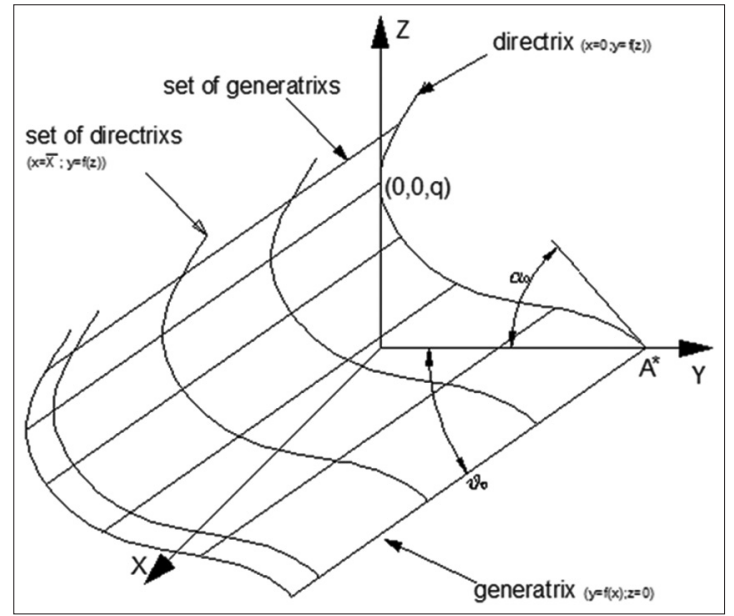

Fig 1. Ruled surface obtained by generatrix and directrix. scalar form of equation (E.01) is represented by the following system of equations:

$$
\left\{\begin{array}{l}
X(u, v)=x_{Q}(u)+v \cos \left(\vartheta_{x}(u)\right) \\
Y(u, v)=y_{Q}(u)+v \cos (\theta(u)) \\
Z(u, v)=z_{Q}(u)+v \cos \left(\vartheta_{z}(u)\right)
\end{array}\right.
$$

where $Q=Q(u)$ is the directrix equation, $\theta=\theta(u)$ is the angle formed by the generatrix horizontal with the direction of motion. $\theta(u)$ can generally be described by a natural cubic spline such as:

$\theta(u)=\theta_{0}+a_{1} u+a_{2} u^{2}+a_{3} u^{3}$

with $\mathrm{a}_{1}, \mathrm{a}_{2}, \mathrm{a}_{3}$ coefficients dimensional and $\theta_{0}$ the main working angle formed by the generatrix of height $z=0$ with the motion direction of the plough. In our case the parametric variable $u$ is represented by the cartesian variable $z$. The direction $\underline{r}=\underline{r}(u)$ is represented, in our case, by a straight line of the plane $(\mathrm{X}, \mathrm{Y})$ given by the equation:

$$
y(\vartheta, x)=\tan \left(\frac{\pi}{2}+\vartheta\right) x+y^{\prime}=\frac{x}{\tan \vartheta}+y^{\prime}
$$

where $y^{\prime}$ is the intercept of the straight line on the ordinate. The equation of the directrix, instead, is assumed as parabolic type:

$(z-q)^{2}=2 p y$ with $x=0$

in which $q$ represents the height of the vertex of the parabola and $p$ is a geometric parameter which is determined by calculating the first derivative of the equation of such directrix at the point $A$ with coordinates $\left(z=0, y=\frac{q^{2}}{2 p}\right)$ and observing that said derivative is related to $\tan \alpha$.

To be precise, we have:

$\tan \left(\frac{\pi}{2}+\alpha\right)=\left.\frac{d y}{d z}\right|_{z=0}=\frac{-q}{p}$

namely:

$$
\frac{1}{\tan \alpha}=\frac{q}{p} p=q \tan \alpha
$$

The directrix equation also allows to calculate the intercept value $y^{\prime}$ of the directrix on the ordinate axis

$$
y^{\prime}=\frac{(z-q)^{2}}{2 p}
$$




\begin{tabular}{|c|c|c|}
\hline$\overline{\mathrm{T}_{x t}}$ & Soil composition (\% sand,\% silt,\% clay,\% organic fraction) & {$[-]$} \\
\hline c & Undrained cohesion unsaturated soil & {$[\mathrm{kN} / \mathrm{m} 2]$} \\
\hline$\rho$ & Apparent density & {$[\mathrm{Kg} / \mathrm{m} 3]$} \\
\hline w & Absolute humidity & $\%$ \\
\hline g & Gravity acceleration & {$[\mathrm{m} / \mathrm{s} 2]$} \\
\hline$\delta$ & Friction angle of soil - working surface & {$\left[{ }^{\circ}\right]-[\mathrm{rad}]$} \\
\hline$\varphi$ & Internal friction angle of the soil in critical condition & {$\left[{ }^{\circ}\right]-[\mathrm{rad}]$} \\
\hline A & Coefficient of adhesion to the working surface & {$[\mathrm{kPa}]$} \\
\hline$b, b_{p}, b_{v}$ & Effective width, effective width edge, effective width plow & {$[\mathrm{m}]$} \\
\hline$d, d_{p}, d_{v}$ & Process depth, process depth of the edge, process depth of the plow & [m] \\
\hline $\mathrm{H}$ & Plow height & [m] \\
\hline L & Plow length & [m] \\
\hline r & Average radius of curvature of the working surface & {$[\mathrm{m}]$} \\
\hline$\theta(\mathrm{z})$ & Main work angle function & {$\left[{ }^{\circ}\right]-[\mathrm{rad}]$} \\
\hline$\theta_{0}, \theta_{\mathrm{u}}$ & Main work angle with $\mathrm{z}=0$ and $\mathrm{z}=\mathrm{H}$ & {$\left[{ }^{\circ}\right]-[\mathrm{rad}]$} \\
\hline$\theta_{\text {ov }}, \theta_{\text {op }}$ & Plow and edge main work angle & {$\left[{ }^{\circ}\right]-[\mathrm{rad}]$} \\
\hline$\theta_{\mathrm{m}}$ & Average main work angle & {$\left[{ }^{\circ}\right]-[\mathrm{rad}]$} \\
\hline$\Delta \theta_{\mathrm{u}}=\theta_{\mathrm{u}}-\theta_{0}$ & Variation of the inclination of horizontal generatrix (angle of last deviation) & {$\left[{ }^{\circ}\right]-[\mathrm{rad}]$} \\
\hline$\Delta \theta_{\mathrm{m}}=\theta_{\mathrm{m}}-\theta_{0}$ & Variation of the inclination of horizontal generatrix (angle of average deviation) & {$\left[{ }^{\circ}\right]-[\mathrm{rad}]$} \\
\hline$\alpha_{0}, \alpha_{p}, \alpha_{v}, \alpha_{u}$ & Attack angle, edge angle of attack, plough angle of attack, angle of exit & {$\left[{ }^{\circ}\right]-[\mathrm{rad}]$} \\
\hline $\mathrm{v}$ & Forward speed & {$[\mathrm{m} / \mathrm{s}]$} \\
\hline$\omega$ & Frequency plough & {$[\mathrm{Hz}]$} \\
\hline$m_{r}$ & Characteristic ratio of rupture & - \\
\hline $\mathrm{N}_{\rho}, \mathrm{N}_{\mathrm{c}}, \mathrm{N}_{\mathrm{a}}$ & Dimensionless factors in function of $\varphi, \delta, \alpha_{\mathrm{p}} e \alpha_{\mathrm{v}}, m_{\mathrm{r}}$ & - \\
\hline
\end{tabular}

At this point we insert the results of equations E.07, E.08 in the equation E.04:

$$
y=\frac{-x}{\tan \left(\vartheta_{0}+\frac{\Delta \theta_{\max }}{H^{2}} z^{2}\right)}+\frac{(z-q)^{2}}{2 q \tan \left(\gamma_{0}\right) \operatorname{sen}\left(\vartheta_{0}\right)}
$$

that represents, for each plane $x=$ cost, parallel to the lateral plane OYZ, a family of profiles as shown in Fig. 1. Therefore, it is possible to represent, parametrically, the working surface of the considered plough. After having obtained the geometric description of the parametric working surface, we can consider its optimization processes.

\section{Optimization}

The understanding of the nature of the relations between the forces that awaken during the process of soil working and the main design parameters of a considered plough are crucial for the design of the tool and the optimization of its energy consumption. The optimization process requires the consistency with the experimental data and a simple analytical and integral structure, which involves very short processing time, in order to be profitably used in the context of optimization cycles which, for their part, involve the computation of multiple solutions. Therefore, the possibility of using costly numerical techniques of integration (CFD, DEM, SHP) (Abo Al-Kheer et al., 2011; Formato and
Faugno, 2007; Kasisira, 2005; Oida and Momozu, 2002; Ros et al., 2008; Rucins and Vilde, 2004; Rucins and Vilde, 2005; Saarilahti, 2002) will be sacrificed on the altar of an analytical - integral approach, which prefers the rapidity of the calculation to the alleged accuracy of the results obtained by differential-algebraic techniques. Among the integral relations, that is possible to find in the vast scientific production that characterizes the subject in question, we have used those developed by Godwin et al., 2007.

According to this approach, the complete expression of the total resistance offered by the engaged tool during the working soil (draught force) Lt [kN] may be considered as the resultant of the component necessary for the rupture of the soil (cut), the component necessary for its lifting and then overturning (inertia) and that generated by the phenomenon of friction and adhesion inside the soil considered and due to the interaction of the latter with the working surface (friction). The draught force is, therefore, expressed as the sum of all the components defined above:

$L_{t}=L_{p}+L_{v}+L_{q 1}+L_{q 2}+L_{a 1}+L_{a 2}+L_{a 3}$

Fwor each of them you have the following analytical representation.

Lp//Lv - Components of the draught force produced by the breaking of the soil 


$$
\begin{aligned}
L_{p}= & {\left[\begin{array}{l}
\left(\varrho g d_{p}^{2} N_{\varrho}+c d_{p} N_{c}\right) \\
\left(b_{p}+0.55 d_{p} \frac{2 m_{r}+1}{3}\right)+\rho v^{2} d_{p} N_{a}\left(b_{p}+0.33 d_{p}\right)
\end{array}\right] } \\
& \operatorname{sen}\left(\alpha_{p}+\delta\right)
\end{aligned}
$$$$
L_{v}=\left(\varrho g d_{v}^{2} N_{\varrho}+c d_{v} N_{c}+\rho v^{2} d_{v} N_{a}\right) b_{v} \operatorname{sen}\left(\alpha_{v}+\delta\right) \operatorname{sen} \theta_{0}
$$

$\mathrm{Lq}_{1} / / \mathrm{Lq}_{2}-$ Components of the draught force produced by the weight and the inertia

$$
\begin{aligned}
& L_{q 1}=\varrho\left(b_{p} d_{p}+b_{v} d_{v}\right) v^{2}\left[1-\left(1-\operatorname{sen} \vartheta_{m} \tan \delta\right) \cos \vartheta_{m}\right] \\
& L_{q 2}=2 \varrho g\left(b_{p} d_{p}+b_{v} d_{v}\right) d_{v}
\end{aligned}
$$

$\mathrm{La}_{1} / / \mathrm{La}_{2} / / \mathrm{La}_{3}-$ Components of the draught force produced by plough ( $1^{\text {st }}$ component $)$ and by the moldboard ( $2^{\text {nd }}$ and $3^{\text {rd }}$ component)

$$
\begin{aligned}
& L_{a 1}=\left(\varrho g d_{v}^{2} N_{\varrho}+c d_{v} N_{c}+\rho v^{2} d_{v} N_{a}\right) b_{v} \operatorname{sen}\left(\alpha_{s}+\delta\right) \cos \theta_{0} \tan \delta \\
& L_{a 2}=\varrho\left(b_{p} d_{p}+b_{v} d_{v}\right) v^{2} \operatorname{sen} \vartheta_{m}\left(1-\operatorname{sen} \vartheta_{m} \tan \delta\right) \tan \delta \\
& L_{a 3}=L \varrho g\left(b_{p} d_{p}+b_{v} d_{v}\right) \tan \varphi \tan \delta
\end{aligned}
$$

For details of this physical - mathematical model see the cited literature.

The comparative geometric analysis of the working surfaces of the modern ploughs, according to the numerous field experiences that can be found in the literature, has led to identifying of the followingbasic parameters fundamental for the efficiency and the efficacy of a soil working (Vilde, 2008). We have referred to them in the definition of the limits of integration of the multi-parametric constrained optimization problems, discussed in the following paragraph (Tables 1 and 2).

The variation law $\theta(z)$ is given by a natural cubic spline, solution of the limits problem E10, where $\theta_{\mu}, \theta_{0}$ are design parameters, while $\Delta \vartheta_{m}=\vartheta_{m}-\vartheta_{0}$ is part of the solution

Table 2: Main geometric parameters of the working surface and characteristic values ${ }^{1}$

\begin{tabular}{llc}
\hline$\theta_{\text {op }}$ & {$\left[^{\circ}\right]$} & $30 \div 32$ \\
$\theta_{\text {ov }}$ & {$\left[^{\circ}\right]$} & $31 \div 42$ \\
$\Delta \theta_{u}=\theta_{u^{\circ}}-\theta_{0}$ & {$\left[^{\circ}\right]$} & $14 \div 17$ \\
$\Delta \theta_{\mathrm{m}}=\theta_{\mathrm{m}}-\theta_{0}$ & {$\left[^{\circ}\right]$} & $9 \div 12$ \\
$\alpha_{\mathrm{p}}$ & {$\left[^{\circ}\right]$} & $18 \div 25$ \\
$\alpha_{\mathrm{v}}$ & {$\left[^{\circ}\right]$} & $18 \div 25$ \\
$\alpha_{\mathrm{u}^{\prime} \min }$ & {$\left[^{\circ}\right]$} & $28 \div 32$ \\
$\alpha_{\mathrm{u}^{\prime} \max }$ & {$\left[^{\circ}\right]$} & $124 \div 130$ \\
$L$ & {$[\mathrm{~m}]$} & $0.80 \div 1.40$ \\
\hline
\end{tabular}

${ }^{1}$ For the considered parameters, the optimal values, min and max that are more performant are shown of the problem of minimum E.11 solved for the considered soil and the assigned depth of process.

$$
\begin{aligned}
& \vartheta(z)-\vartheta_{0}=a_{0}+a_{1} z+a_{2} z^{2}+a_{3} z^{3}
\end{aligned}
$$

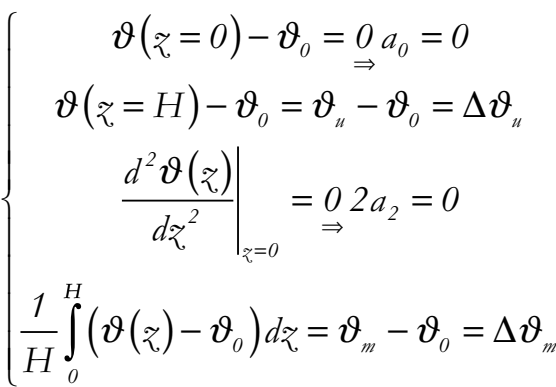

Condition of the minimum of draught force

$$
\min \left[\operatorname{Tiro}\left(\alpha, \vartheta_{0}, \Delta \vartheta_{m}, v\right)\right] \text { with }
$$

$\alpha_{m \text { in }} \leq \alpha \leq \alpha_{m a x}$

$\vartheta_{0, \text { m in }} \leq \vartheta_{0} \leq \vartheta_{0, \text { max }}$

$\Delta \vartheta_{m, \min } \leq \Delta \vartheta_{m} \leq \Delta \vartheta_{m, \max }$

$v_{m \text { in }} \leq v \leq v_{m \text { max }}$

The system relative to the coefficients of the expression $\left(\vartheta(z)-\vartheta_{0}\right)$ is reduced, easily, to the following system of two equations in two variables:

$$
\left\{\begin{array} { c } 
{ a _ { 0 } = 0 } \\
{ 2 a _ { 2 } = 0 } \\
{ a _ { 1 } + H ^ { 2 } a _ { 3 } = \frac { \Delta \vartheta _ { u } } { H } } \\
{ 2 a _ { 1 } + H ^ { 2 } a _ { 3 } = 4 \frac { \Delta \vartheta _ { m } } { H } }
\end{array} \left\{\begin{array}{c}
a_{1}+H^{2} a_{3}=\frac{\Delta \vartheta_{u}}{H} \\
2 a_{1}+H^{2} a_{3}=4 \frac{\Delta \vartheta_{m}}{H}
\end{array}\right.\right.
$$

where $\Delta \vartheta_{m}$ is the value resulted from the minimization of the draught force.

The solution of this system can be derived analytically:

$a_{1}=\frac{-1}{H}\left(\Delta \vartheta_{u}-4 \Delta \vartheta_{m}\right)$ and $a_{3}=\frac{2}{H^{3}}\left(\Delta \vartheta_{u}-2 \Delta \vartheta_{m}\right)$

These results allow us to write that:

$$
\begin{aligned}
\vartheta(z)= & \vartheta_{0}-\frac{1}{H}\left(\Delta \vartheta_{u}-4 \Delta \vartheta_{m}\right) z \\
& +\frac{2}{H^{3}}\left(\Delta \vartheta_{u}-2 \Delta \vartheta_{m}\right) z^{3}
\end{aligned}
$$

This analytical approach has allowed to obtain the program code ARAT1, made in Matlab environment, such that, given 
the input parameters: $\mathrm{H}, \mathrm{L}, \mathrm{dp}, \mathrm{dv}, \mathrm{bp}, \mathrm{bv}, \mathrm{A}, \mathrm{Cu}, \delta, \varphi, \varrho$, allows to calculate the values of the components of the draught force $\left(L_{p}, L_{v}, L_{q 1}, L_{q 2}, L_{a 1,} L_{a 2}, L_{a 3}\right)$ and, therefore, to determine the optimum values of the parameters: $\alpha, \vartheta$, $\Delta \vartheta$ and the optimum speed of the process.

\section{Experimental tests}

The entire process, previously exposed, has been applied to a commercially available plough, performing the optimization of the working surface for a considered soil. Starting from a set of points considered on the cross sections of the working surface of the plough considered (Fig. 2) the analytical parameterized expression of the considered working surface was obtained.

The sections were examined in a reference system defined in the following way:

- Y-axis: Longitudinal axis of the plough, which coincides with the forward direction of the plough;

- X-axis: Transverse axis of the plough, perpendicular to the plane of the wall of the plough;

- Z-axis: Vertical axis of the plough, perpendicular to the $\mathrm{X}-\mathrm{Y}$ plane.

For each examined section, the points belong to the curves of intersection of the plough working surface with the $\mathrm{X}-\mathrm{Z}$ plane (Plans with $y=$ const.) at intervals of about $40 \mathrm{~mm}$ in the $y$ direction. The step along the $z$-axis is not greater than $20 \mathrm{~mm}$. Therefore, the maximum net considered was not greater than $20 \times 40 \mathrm{~mm}$. The geometric parameters characteristic of this working surface were evaluated. The interaction between soil and considered working surface was also studied, examining a particular type of soil whose physical properties are shown in Table 3.

Later, using the optimization program code ARAT1 described previously, the optimal values of the geometric parameters, that define the working surface, were determined, so as to provide the minimum value of the resistance force during the soil-plough interaction. In Fig. 2 the representation of the cloud of points of the section of the considered plough is shown. To compare the section points and the elaborated points we have slightly modified the function y (E.09)

$$
y=\frac{x}{\tan \left(\vartheta_{0}+\frac{\Delta \theta_{\max }}{H^{2}} z^{2}\right)}-\frac{z^{2}-2 q z}{2 q \tan \left(\gamma_{0}\right) \operatorname{sen}\left(\vartheta_{0}\right)}-y_{0}
$$

Table 3: Physical and mechanical parameters of the considered soil

\begin{tabular}{|c|c|c|c|c|c|c|c|c|c|}
\hline \multirow[t]{2}{*}{ soil } & \multicolumn{4}{|c|}{ (g/kg) } & \multirow{2}{*}{$\frac{w}{\mathrm{Kg} / \mathrm{m}^{3}}$} & \multirow{2}{*}{$\frac{\rho}{k N / m^{2}}$} & \multirow[t]{2}{*}{ C } & \multirow{2}{*}{$\frac{\varphi}{\circ}$} & \multirow[t]{2}{*}{$\delta$} \\
\hline & Sand & Silt & Clay & Humus & & & & & \\
\hline S1 & 64,0 & 19,0 & 17,0 & 1,7 & 176.0 & 13,3 & 11.2 & 29 & 16 \\
\hline
\end{tabular}

The change depends on a different origin in the reference systems used, respectively, in the equation E.09 and sections considered. Therefore for the considered plough, the following values of the parameters, which allow the analytical description of the considered working surface, were obtained:

$\vartheta_{0}=45^{\circ} \quad \gamma_{0}=29^{\circ} \quad q=43 \mathrm{~cm}$ with $H=100 \mathrm{~cm}$ and $y_{0}=20 \mathrm{~cm}$ (the latter two values set initially).

These values give a $S Q M=1.3$ (mean square deviation).

In Fig. 3 shows the surface resulting from E.12 equation using the previously obtained values.

\section{RESULTS AND DISCUSSION}

\section{Sensitivity analysis}

The parametric geometry of the working surface of the considered plough was examined in the study of soilplough interaction in relation to the considered soil whose

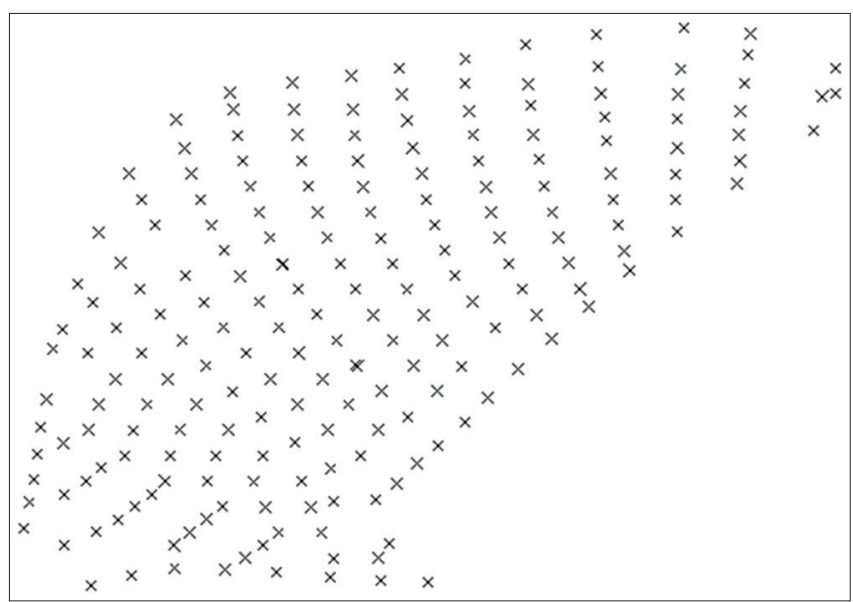

Fig 2. Representation of the point cloud of section of considered plough.

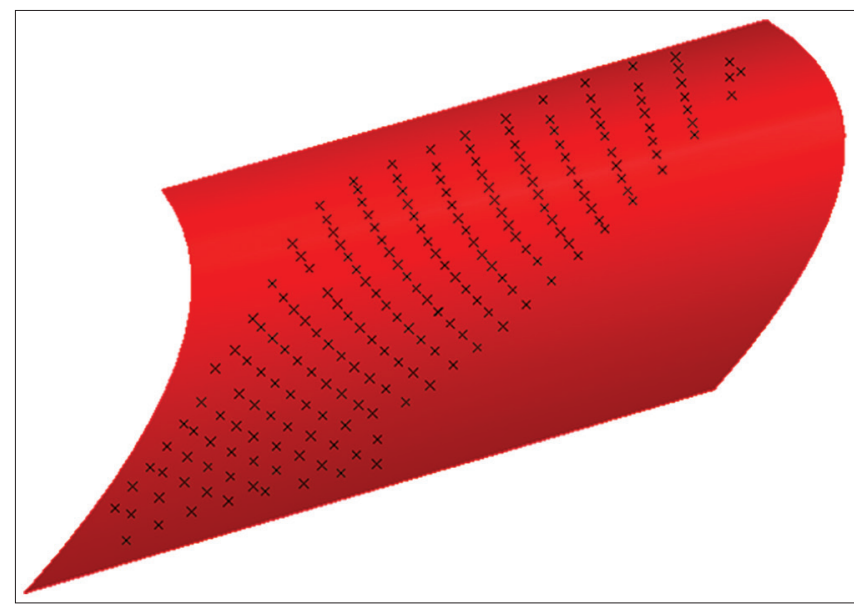

Fig 3. Resulting surface using the obtained values. 
characteristic parameters are reported in Table 3. The geometrical and process characteristics of the considered plough are shown in the following Table 4 . For the process speed, the working range of 1 to $5[\mathrm{~m} / \mathrm{s}]$ is considered. The results of sensitivity analysis carried out for the considered working surface, the soil and the process conditions, are shown in Figs. 4-6.

Fig. 4 shows the trends of the components $L_{p}, L_{v}, L_{q 1}$ and $L_{a 1}$ of the total draught force for the geometry of the considered plough, as compared to the velocity $\mathrm{v}$ and the angle $\alpha$ for the first, second and fourth component, while for the third component we reported its dependence on the angle of deviation $\Delta \theta$ and the speed $\mathrm{v}$.

In Fig. 5, however, the trend of the component $L_{q 2}$ is shown in function of the main work angle $\vartheta_{0}$, the trend of the components $L_{a 2}$ and $L_{a 3}$ in function of the speed $\mathrm{v}$ and at last the behavior of the component $L_{a 3}$ is reported in function of both the velocity $\mathrm{v}$, of the length of the considered plough.

Fig. 6 represents the trend of the total force $\left(L_{t o t}\right)$, for the geometry of the considered plough, with respect to the angle $\alpha$, to the velocity $\mathrm{v}$ and to the main work angle $\theta_{0}$.

Table 4: Geometric and process parameters of the considered plough

\begin{tabular}{llc}
\hline bp & {$[\mathrm{m}]$} & 0.100 \\
$\mathrm{bv}$ & {$[\mathrm{m}]$} & 0.205 \\
$\mathrm{dp}$ & {$[\mathrm{m}]$} & 0.300 \\
$\mathrm{dv}$ & {$[\mathrm{m}]$} & 0.310 \\
$\mathrm{~L}$ & {$[\mathrm{~m}]$} & 0.850 \\
$\mathrm{H}$ & {$[\mathrm{m}]$} & 1.00 \\
\hline
\end{tabular}

Finally we report some parametric graphs of the total draught force and of its components in function of the angle $\alpha$, of the deviation angle $\Delta \theta$ with the velocity $\mathrm{v}$ as parameter, for the geometry of the working surface of the considered plough (Fig. 7).

Subsequently the conditions of minimum draught force (function $L_{t}$ ) for the optimization process have been determined.

\section{Optimization of the working surface for the considered soil}

By using the program code ARAT1 described previously, and using the values of the input parameters shown in Table 3 and Table 4, we have obtained optimum values of the geometrical parameters and process, listed below in Table 5 .

With these parameter values, obtained by the considered optimization process, it was possible to get the analytical expression of the working optimized surface. Below (Fig. 8) is shown a graphic comparison between the original surface (green) of the plough in question and the surface of that one optimized (red).

It is possible to notice a different curvature between the profiles of the two surfaces, this is due to the fact that the curvature depends on the angle $\alpha$, in fact, remembering that $\tan \alpha=\tan \gamma \sin \theta$ and that $\left|\frac{d^{2} y}{d z^{2}}\right|=\frac{1}{q \tan \left(\gamma_{0}\right) \operatorname{sen}\left(\vartheta_{0}\right)}$, one has that a larger value of $\alpha$ implies a value less than the the second derivative. Another difference between the two profiles resides in the main work angle $\left(\vartheta_{0}\right)$, which directly influences the inclination of the generatrix line (E. 04). The last parameter, elaborated in the optimization

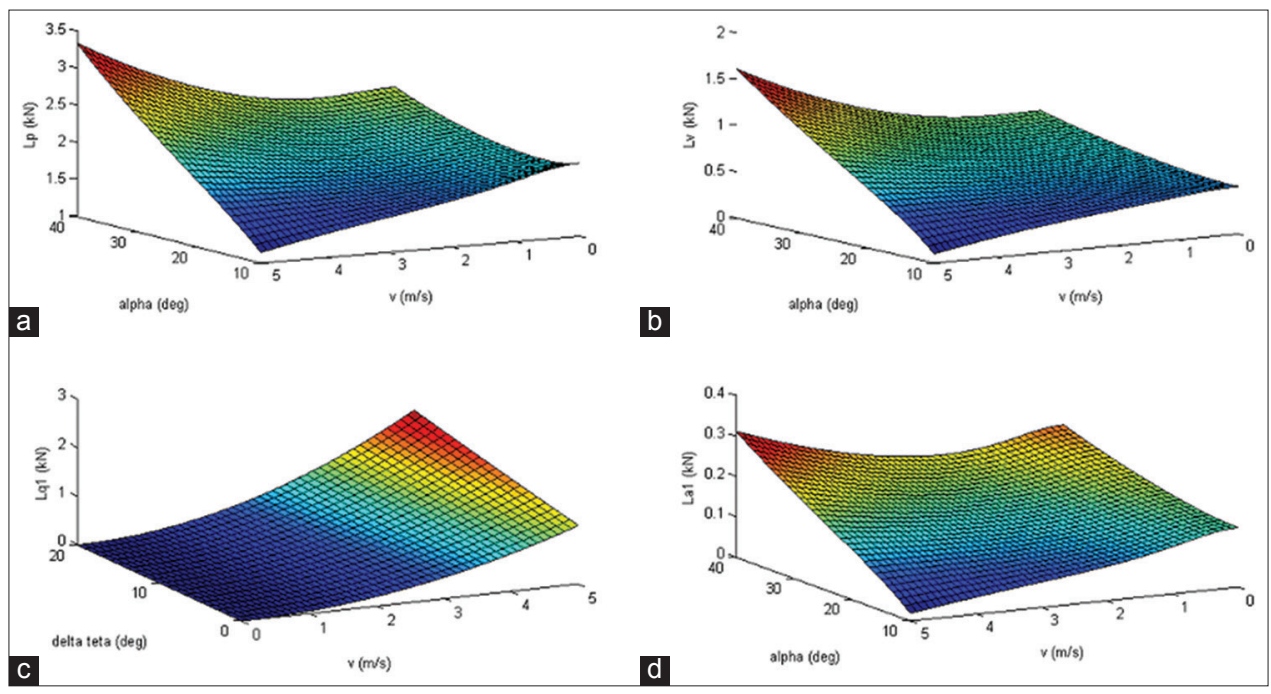

Fig 4. Diagrams of the components $L_{p}, L_{v}, L_{q 1}$ and $L_{a 1}$ of the total drag force for the geometry of the considered plough, as compared to the velocity $v$ and the angle $\alpha$ for the first (a), second (b) and fourth component (d), while for the third component we reported its dependence by the angle of deviation $\Delta \theta$ and the speed $v(\mathrm{c})$. 


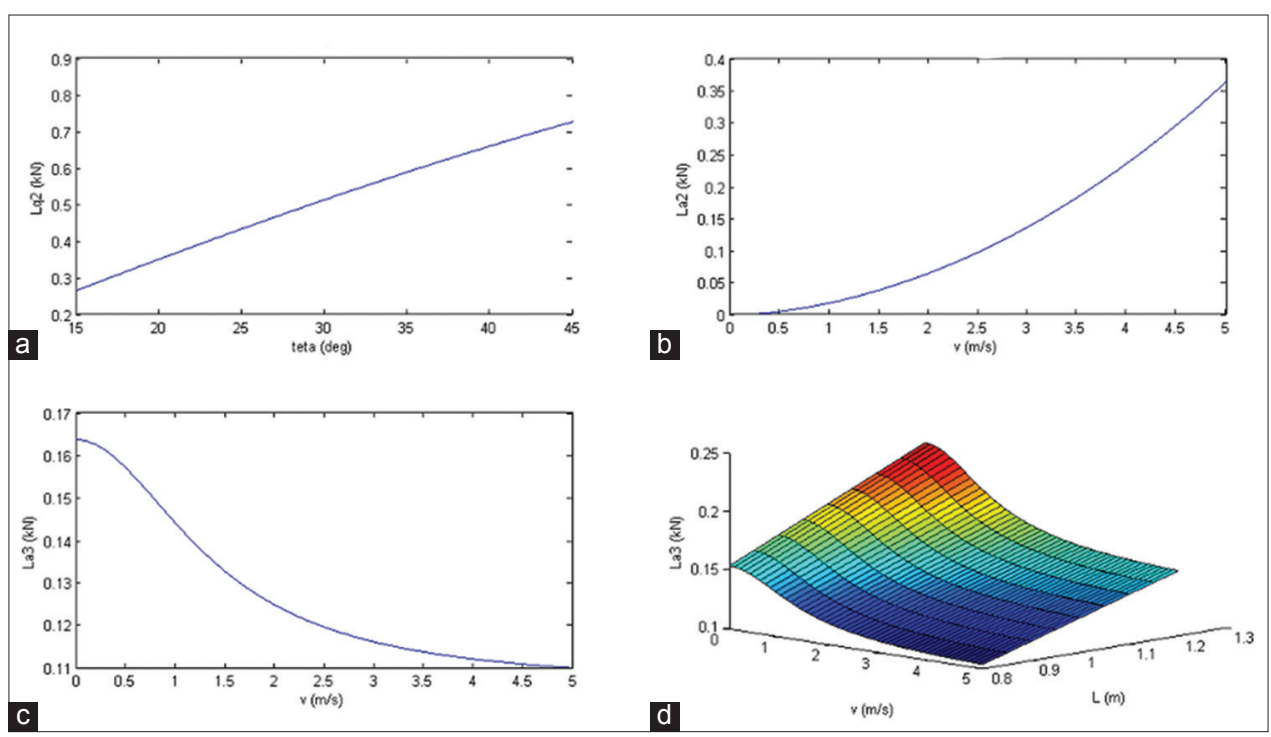

Fig 5. Diagram of the component $L_{q 2}$ as a function of the main work angle $\vartheta_{0}\left(\right.$ a), the performance of the components $L_{a 2}$ and $L_{a 3}$ as a function of the speed $v(b),(c)$ and finally is reported the behavior of the component $L_{a 3}$ as a function of both the velocity $v$ and of the length of the considered plough (d).

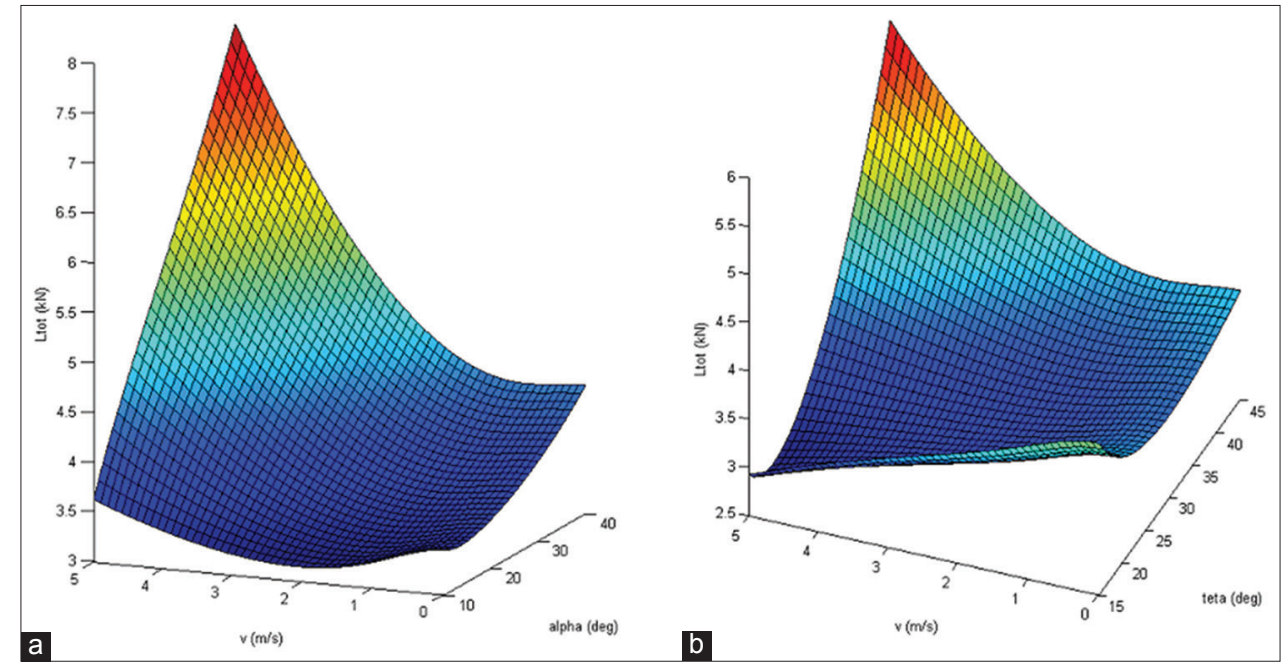

Fig 6. Diagram of the total force ( $L_{t o t}$ ) with respect to the angle $\alpha$ and to the speed $v$ (a) and to the main work angle $\vartheta_{0}$ (b) for the geometry of the considered plough.

Table 5: Optimum values of the geometric and process parameters that minimize the drag force

\begin{tabular}{cccccc}
\hline Tiro & $\boldsymbol{\alpha}_{\text {op }}$ & $\boldsymbol{\alpha}_{\text {ov }}$ & $\boldsymbol{\theta}_{0}$ & $\boldsymbol{\theta}_{\mathbf{u}}-\boldsymbol{\theta}_{\mathbf{0}}$ & $\mathbf{v}$ \\
\hline$[\mathrm{kN}]$ & {$[\mathrm{deg}]$} & {$[\mathrm{deg}]$} & {$[\mathrm{deg}]$} & {$[\mathrm{deg}]$} & {$[\mathrm{m} / \mathrm{s}]$} \\
3.19 & 20.0 & 20.0 & 35.0 & 15.00 & 1.70 \\
\hline
\end{tabular}

process, is speed. It, for values of $\alpha$ greater than $15^{\circ}$, has an almost proportional effect on the components of the drag force.

\section{CONCLUSIONS}

Optimal solutions reported in Table 5 say anything about the effectivity of the process, measurable ex post on the basis of the indexes of texture, grain size and overturning of the worked soil (agronomic quality of the soil working). Moreover, the gap between the solutions obtained to vary of the initial state of the considered soil, even obtained with an integral-analytical model, certainly less approximative then a differential-algebraic approach, indicates the fact that the problem of the optimization of the working surface in concerns of energy efficiency, as well as traditionally studied, must be related to the complete "physical state" of the soil considered, and therefore considering for it only the conditions of "tempering soil"; in fact, as is known, an agricultural soil can be subjected to mechanical working only if it is in a condition of "tempering", i.e. unsaturated soil and away from the point of saturation, generally with 

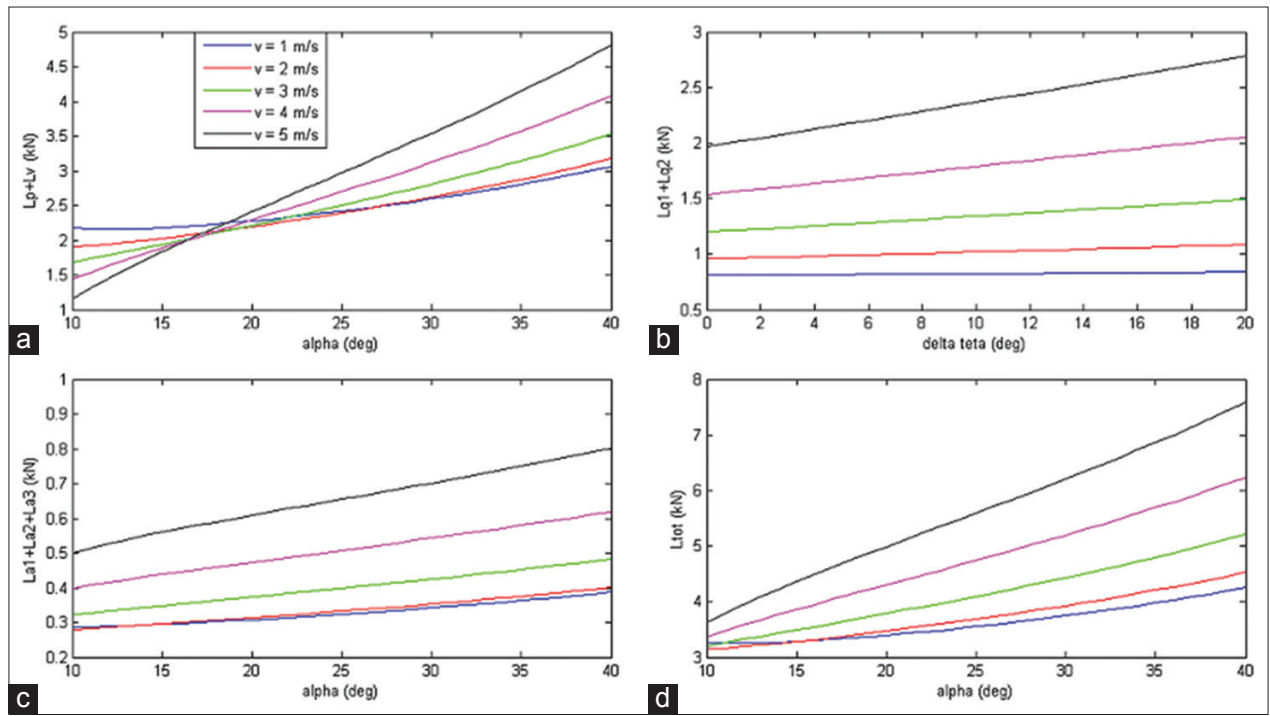

Fig 7. Parametric graphs of the total force (d) and its components (a), (c) as a function of the angle $\alpha$, of the angle of deviation $\Delta \theta$ (b) with velocity $v$ as parameter, for the geometry of the considered working surface plough.

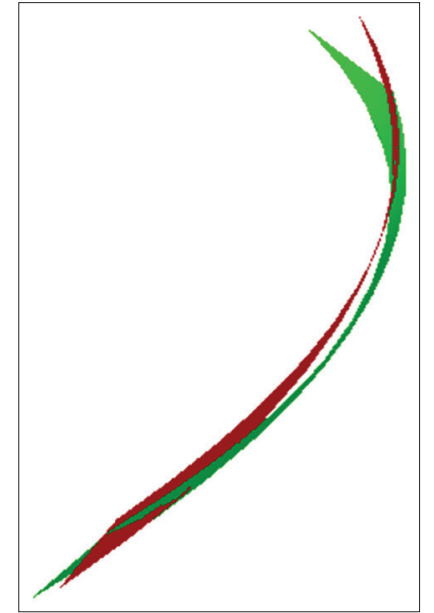

Fig 8. Graphical comparison between the original surface (green) of the plough in question and the optimized one (red).

humidity $\mathrm{u}<10 \%$. Generally a soil, by the effect of weather vicissitudes, undergoes continuous changes of physical state, which could make it be able to ward off from the operating condition of "tempering". For soils that are found in such physical condition (with $\mathrm{u}>>10 \%$ ) and with values of $u$ which also vary in the spatial domain of processing, it is possible to note that, if you wish to apply, as simple theoretical and speculative exercise, a traditional deterministic analysis, although based on sophisticated and expensive numerical techniques (i.e., techniques DEM), one could not solve, "reasonably" and unequivocally, the problem of the definition of an optimal working surface or that of the estimate of the draught force and of the components of the force that awaken during the soil working. This limitation can be overcome only in a probabilistic perspective, through forecasting models (Monte Carlo, FORM, SORM) that evaluate explicitly the epistemic nature of the soil and the inherent uncertainty of its physical and mechanical properties. In conclusion, the results obtained may be applied with a certain validity, if we consider only the physical conditions of the soil "in tempering", which are the actual conditions of the soil subjected to mechanical working. These, according to studies and surveys carried out, also ensure the "consistency" of the characteristics of the soil, around the spatial domain and for the duration of processing; in fact, in a lot of examined agricultural soils was found a good "constancy" of the physical and mechanical characteristics of the agricultural soil in the operating conditions of "tempering".

\section{Author's contributions}

All the authors equally contributed to carry out the research whose results are reported in this work.

\section{REFERENCES}

Abo Al-Kheer, A., M. G. Kharmanda, A. El Hami and A. M. Mouazen. 2011. Estimating the variability of tillage forces on a chisel plough shank by modeling the variability of tillage system parameters. Comput. Electron. Agric. 78: 61-70.

Formato, A., S. Faugno and G. Paolillo. 2004. Comparison between different types of soil working to prepare an agricultural soil. In: Proceedings of AgEng 2004 Conference Engineering the Future, Publisher Technological Institute of Leuven, Belgium, pp. 76-81.

Formato, A., S. Faugno and G. Paolillo. 2004. Numerical modelling of a plough mouldboard surface. In: Proceedings of AgEng 2004 Conference Engineering the Future, Publisher Technological Institute of Leuven, Belgium, pp. 36-41.

Formato, A. 2005. Simplified triaxial apparatus to test agricultural soils. Soil Tillage Res. 81(1): 121-129.

Formato, A., S. Faugno and G. Paolillo. 2005. Numerical simulation of the interaction between soil and plough mouldboard. Biosyst. 
Eng. 93: 309-316.

Formato, A. and S. Faugno. 2007. Numerical simulation of an agricultural soil shear stress test. J. Agric. Eng. 1: 37-42.

Formato, A. and M. Carillo. 2008a. Determination of the mechanical behaviour of agricultural soil by numerical simulation. In: A. Formato, (Ed.), Advance in Soil and Tillage Research, Transworld Research Network, Kerala, India, pp. 29-44.

Formato, A. and M. Carillo. 2008b. Study of soil-plough moulboard interaction. In: A. Formato, (Ed.), Advance in Soil and Tillage Research, Transworld Research Network, Kerala, India, pp. 45-60.

Formato, A., G. P. Pucillo and A. Abagnale. 2013. Study of sandy soil compaction. J. Agric. Sci. Technol. A. 3: 356-367.

Gill, W. R. and G. E. Vanden Berg. 1968. Soil Dynamics in Tillage and Traction, Agriculture Handbook No. 316, ARS, USDA, Washington, DC

Godwin, R. J., M. J. O' Dogherty, C. Saunders and A. T. Balafoutis. 2007. A force prediction model for mouldboard ploughs incorporating the effects of soil characteristic properties, plough geometric factors and ploughing speed. Biosyst. Eng. 97: 117-129.

Goryachkin, V. P. 1968. Collected Works in Three Volumes, Kolos, Moscow.

Jia, X. 2004. Theoretical analysis of the adhesion force of soil to solid materials. Biosyst. Eng. 87: 489-493.

Jayasuriya, H. P. W. and V. M. Salokhe. 2001. SW-soil and water: A review of soil-tine models for a range of soil conditions. J. Agric. Eng. Res. 79: 1-13.

Jeshvaghani, H. S., S. K. H. Dehkordi, M. F. Samani and H. R. Dehkordi. 2013. Comparison and optimization of graphical methods of moulboard pough bottom design using computational simulation. J. Am. Sci. 9: 414-420.

Kasisira, L. 2005. Force Modeling and Energy Optimization for Subsoilers in Tandem. Ph.D. Dissertation, University of Pretoria, Pretoria, South Africa.

Mouazen A. M. and H. Ramon. 2008. Expanding a bulk density model for on-line measurement of soil compaction in new soil textures. In: A. Formato, (Ed.), Advance in Soil and Tillage Research, Transworld Research Network, Kerala, India, pp. 105-124.

Oida, A. and M. Momozu. 2002. Simulation of soil behavior and reaction by machine part by means of DEM. Agric. Eng. Int. CIGR J. Sci. Res. Dev. 4: 210-221.

Ren, L. Q., J. Tong, J. Q. Li and B. C. Chen. 2001. Soil adhesion and biomimetics of soil-engaging components: A review. J. Agric. Eng. Res. 79: 239-263.

Ros, V., R. J. Smith, S. J. Marley and D. C. Erbach. 2008. Mathematical modeling and computer-aided design of passive tillage In: A. Formato (Ed.), Advance in Soil and Tillage Research, Transworld Research Network, Kerala, India, pp. 61-80.

Rucins, A. and A. Vilde. 2004. Mathematical modelling of the operation of plough bodies to determine their draft resistance and optimum parameters. In: TEKA Commission of Motorization and Power Industry in Agriculture, Polish Academy of Sciences Branch in Lublin. Lublin, Poland, pp. 177-184.

Rucins, A. and A. Vilde. 2005. Modelling forces acting on the plough body. Simulation in Wider Europe. In: Proceedings of $19^{\text {th }}$ European Conference on Modelling and Simulation ECMS 2005. Publisher ECMS, Riga, Latvia, pp. 414-419.

Saarilahti, M. 2002. Soil interaction model. In: Haarlaa, R. and J. Salo (Eds.), ECOWOOD Studies Made at the University of Helsinki, University of Helsinki, Faculty of Agriculture and Forestry, Department of Forest Resource Management, University of Helsinki.

Shrestha, D. S., G. Singh and G. Gebresenbet. 2001. PM-power and machinery: Optimizing design parameters of a mould board plough. J. Agric. Eng. Res. 4: 377-389.

Soni, P. and V. M. Salokhe. 2006a. Theoretical analysis of microscopic forces at soil-tool interfaces: A review. Agric. Eng. Int. CIGR J. 3: 101-115.

Soni, P. and V. M. Salokhe. 2006b. Influence of dimensions of UHMW-PE protuberances on sliding resistance and normal adhesion of Bangkok clay soil to biomimetic plates. J. Bionic Eng. 3: 63-71.

Soni, P., V. M. Salokhe and H. Nakashima. 2007. Modification of a mouldboard plough surface using arrays of polyethylene protuberances. J. Terramechanics. 44: 411-422.

Vilde, A. and A. Rucins. 2008. Simulation of the impact of the plough body parameters, soil properties and working modes on the ploughing resistance. In: Proceeding of Tenth International Conference on Computer Modeling and Simulation, UKSIM 08, Publisher IEEE, USA, pp. 697-702.

Vilde, A. and W. Tanaś. 2005. Determination of the soil friction coefficient and specific adhesion. In: TEKA Commission of Motorization and Power Industry in Agriculture, Polish Academy of Sciences Branch in Lublin, Lublin, Poland, pp. 212-216.

Vilde, A. 2004. Mechanical and mathematical foundations for modelling the dynamics of soil tillage machine operating parts. In: TEKA Commission of Motorization and Power Industry in Agriculture, Polish Academy of Sciences Branch in Lublin, Lublin, Poland, pp. 228-236.

Vilde, A. and Rucins, A. 2004. The impact of soil physical and mechanical properties on draft resistance of ploughs. In: TEKA Commission of Motorization and Power Industry in Agriculture, Polish Academy of Sciences Branch in Lublin, Lublin, Poland, pp. 243-248. 